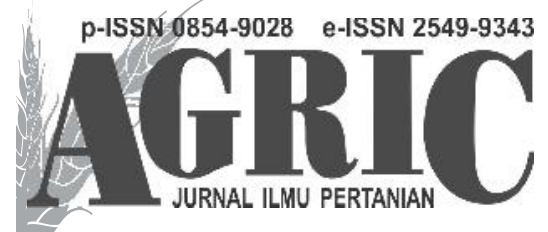

Fakultas Pertanian dan Bisnis Universitas Kristen Satya Wacana

Jl. Diponegoro 52-60 SALATIGA 50711 - Telp. 0298-321212 ext 354

email: jurnal.agric@adm.uksw.edu, website: ejournal.uksw.edu/agric

Terakreditasi Kementrian Riset, Teknologi dan Pendidikan Tinggi berdasarkan SK No 21/E/KPT/2018

\title{
PERSEPSI PETANI TERHADAP BUDIDAYA GANDUM TROPIS
}

\author{
M. Alfian Happy Pramuditya dan Tinjung Mary Prihtanti \\ Program Studi Agribisnis, Fakultas Pertanian dan Bisnis \\ Universitas Kristen Satya Wacana, Jl. Diponegoro 52-60 Salatiga 50711, Indonesia \\ E-mail: tinjung.prihtanti@uksw.edu
}

Diterima: 7 Agustus 2019, disetujui, 13 Desember 2019

\begin{abstract}
Indonesia tried to cultivated wheat since 2000. Characteristics of Indonesia as a tropical country caused the productivity of wheat crops was relatively lower than the productivity of sub-tropical wheat cultivation. The development of wheat cultivation was carried out in various regions, including in Central Java Province. Several institutions had participated to introduce the wheat cultivation in Central Java province. This study explores the farmer perceptions on wheat farming and correlation between internal driver and external driver and farmer's perception on wheat farming, and the correlation between farmer perception toward farmer motivation to cultivate wheat. This research used survey technique to collect primary data from farmers who get involved on wheat cultivation introduction program. Data analysis techniques were used rank spearman correlation analysis. The study showed that respondents in Demak Regency tend to have the perception that wheat cultivation is very unprofitable, not easily cultivated and has a high risk of crop failure. Respondents in Boyolali tend to have the perception that wheat is easily cultivated, but has a high risk of crop failure and high selling prices. Respondents in Klaten Regency tend to have the perception that wheat cultivation is not profitable and has a high risk of crop failure, but has a high selling price. There is no significant relationship on age, education, farming experience, frequency of extension, and farm environmental conditions on farmers' perceptions. There are significant relationship between farmer status, land area, with farmers' perception on wheat cultivation, and the farmers perception had relation with farmers motivation to cultivate wheat .
\end{abstract}

Keywords: wheat, farmer characteristic, perception, correlation, Central Java 


\begin{abstract}
ABSTRAK
Indonesia berusaha membudidayakan gandum sejak tahun 2000. Karakteristik Indonesia sebagai negara tropis menyebabkan produktivitas tanaman gandum relatif lebih rendah daripada produktivitas budidaya gandum sub-tropis. Pengembangan budidaya gandum dilakukan di berbagai daerah, termasuk di Provinsi Jawa Tengah. Beberapa lembaga telah berpartisipasi untuk memperkenalkan budidaya gandum di Provinsi Jawa Tengah. Studi ini mengeksplorasi persepsi petani tentang pertanian gandum dan korelasi antara driver internal dan driver eksternal dengan persepsi petani tentang pertanian gandum, dan korelasi antara persepsi petani terhadap motivasi petani untuk menanam gandum. Penelitian ini menggunakan teknik survei untuk mengumpulkan data primer dari petani yang terlibat dalam program pengenalan budidaya gandum. Teknik analisis data digunakan dalam analisis korelasi rank spearman. Studi menunjukkan bahwa responden di Kabupaten Demak cenderung memiliki persepsi bahwa budidaya gandum sangat tidak menguntungkan, tidak mudah diolah dan memiliki risiko kegagalan panen yang tinggi. Responden di Boyolali cenderung memiliki persepsi bahwa gandum mudah dibudidayakan, tetapi memiliki risiko kegagalan panen yang tinggi dan harga jual yang tinggi. Responden di Kabupaten Klaten cenderung memiliki persepsi bahwa budidaya gandum tidak menguntungkan dan memiliki risiko kegagalan panen yang tinggi, tetapi memiliki harga jual yang tinggi. Tidak ada hubungan yang signifikan dalam hal usia, pendidikan, pengalaman bertani, frekuensi penyuluhan, dan kondisi lingkungan pertanian dengan persepsi petani. Ada hubungan yang signifikan antara status petani, luas lahan, dengan persepsi petani tentang budidaya gandum, dan persepsi petani memiliki hubungan dengan motivasi petani untuk menanam gandum.
\end{abstract}

Kata kunci: gandum, karakteristik petani, persepsi, korelasi, Jawa Tengah

\section{PENDAHULUAN}

Diversifikasi tanaman pangan dan diversifikasi pangan merupakan salah satu strategi pemerintah untuk meningkatkan kesejahteraan petani dan mengurangi ketergantungan terhadap konsumsi beras. Indonesia mencoba membudidayakan gandum sejak awal abad ke-18, akan tetapi tidak pernah menjadi tanaman penting dalam sistem usahatani. Pengembangan gandum telah ditempuh pemerintah. Upaya pengembangannya diawali oleh Kementerian Pertanian melalui uji adaptasi gandum pada tahun 1978.

Pengembangan komoditas gandum dirasa semakin penting mengingat semakin meningkat pesatnya konsumsi masyarakat akan aneka pangan berbahan baku tepung gandum. Banyak industri makanan di Indonesia menggunakan gandum sebagai bahan utamanya, sehingga gandum sangat potensial untuk dibudidayakan dan dikembangkan. Pengembangan gandum secara bertahap diujicoba dan disebarluaskan kepada masyarakat oleh beberapa lembaga, baik Lembaga pemerintah, Lembaga swadaya masyarakat, Lembaga penelitian, maupun Lembaga Pendidikan. Di Indonesia gandum dapat tumbuh dengan baik pada ketinggian $>800 \mathrm{~m}$ di atas permukaan laut dengan suhu $10-28^{\circ} \mathrm{C}$, namun masih bisa dibudidayakan pada ketinggian $\pm 400 \mathrm{~m}$ di atas permukaan laut meskipun produktivitas yang diperoleh lebih rendah (Nur et al., 2012). Varietas gandum yang telah dikembangkan di Indonesia termasuk varietas Nias, Timor, Selayar, Guri, dan Dewata. Karakteristik Indonesia sebagai negara tropis menyebabkan produktivitas tanaman gandum relatif lebih rendah dibandingkan produktivitas budidaya gandum sub-tropis. 
Budidaya gandum diharapkan menjadi alternatif pertanian bagi petani yang dapat mendukung kebutuhan protein keluarga dan mengurangi penggunaan tepung dalam skala kecil. Penelitian oleh Kurnia et al (2016), kendala dalam mengembangkan budidaya gandum adalah persaingan dengan tanaman lain yang umumnya ditanam oleh petani dan kurangnya pengetahuan petani tentang pertanian gandum. Di sisi lain, varietas gandum untuk daerah tropis dataran rendah masih dalam proses penelitian hingga saat ini, termasuk melalui upaya untuk bermutasi gen, menguji adaptasi, atau memperkenalkan genotipe baru. Sembiring et al (2013) menyatakan bahwa budidaya gandum belum memberikan keuntungan yang layak secara ekonomis mengingat produksi masih rendah. Oleh karena itu, untuk mewujudkan keberhasilan pengembangan gandum dapat dilakukan melalui integrasi antara subsistem produksi, pengolahan dan pemasaran hasilnya, sehingga gandum dapat memberi manfaat bagi petani.

Beberapa kabupaten di Jawa Tengah telah mencoba melakukan budidaya gandum pada tahun 2017, yaitu di Kabupaten Boyolali, Klaten, dan Demak. Uji coba budidaya tersebut diinisiasi dan didampingi oleh Fakultas Pertanian dan Bisnis Universitas Kristen Satya Wacana dalam bentuk kegiatan penelitian dan pengabdian masyarakat, dimana budidaya gandum dilakukan di bulan Juli / Agustus dan dipanen pada akhir Oktober/November (di luar musim tanam ideal). Harapan dari upaya pengenalan budidaya gandum tersebut adalah memberikan dorongan bagi petani untuk melakukan diversifikasi tanaman yang dapat mendukung ketahanan pangan masyarakat.
Respon petani dari hasil kegiatan tersebut perlu dilihat melalui kajian persepsi karena persepsi akan membentuk respon perilaku.

Persepsi adalah proses yang dimulai dari visi hingga membentuk respons yang terjadi pada individu, sehingga individu sadar akan segala sesuatu di lingkungannya melalui indera mereka (Morgan, 1966). Karakteristik seseorang mempengaruhi persepsinya, sedangkan persepsi itu akan mempengaruhi tindakan atau perilakunya (Roger dan Shoemaker, 1971). Persepsi petani terhadap budidaya gandum dipengaruhi oleh dua faktor, yaitu faktor eksternal dan faktor internal. Faktor eksternal adalah faktor yang berasal dari luar petani dan faktor internal adalah faktor yang berasal dari dalam diri petani itu sendiri. Hongbin-Liu dan Xiaojun Luo (2018) menyatakan bahwa external driver memainkan peran yang lebih penting dalam membentuk persepsi perlindungan lahan petani. Selain itu, teori perilaku kognitif menunjukkan bahwa kesadaran, persepsi, motivasi, dan perilaku saling berhubungan.

Mengacu teori proses persepsi (Ahmadi, 1986), Persepsi merupakan unsur penting dalam menyesuiakan perilaku dan lingkungannya. Persepsi mempengaruhi perilaku, terbentuknya sikap dan perasaan, dimana khususnya terjadinya perilaku didahului dengan proses termotivasinya seseorang. Winardi (2000) menyatakan bahwa motivasi adalah faktor-faktor yang ada dalam diri seseorang yang menggerakkan dan merangsangnya untuk melakukan tindakan-tindakan. Salah satu indicator motivasi yakni gairah kerja atau semangat untuk melakukan pekerjaan. Burgess (1971) menyimpulkan bahwa ada tujuh keinginan motivasi: 
untuk mengetahui, untuk mencapai tujuan pribadi, untuk mencapai tujuan sosial, untuk mencapai tujuan keagamaan, untuk melarikan diri, untuk mengambil bagian dalam kegiatan sosial, dan untuk mematuhi formal.

Berdasarkan pertimbangan pentingnya mendukung pengembangan budidaya gandum dan dikaitkan teori yang ada, maka dapat disimpulkan bahwa ada alasan teoretis dan praktis yang penting untuk menyelidiki persepsi petani dan korelasinya dengan faktor-faktor internal dan eksternal, juga korelasi antara persepsi dan motivasi. Oleh karena itu, penelitian ini bertujuan untuk menguji secara empiris persepsi petani tentang budidaya gandum dan untuk mengetahui hubungan antara persepsi petani tentang budidaya gandum di Jawa Tengah dengan umur petani, pendidikan petani, pengalaman bertani, motivasi individu untuk menanam tanaman alternatif, luas lahan, frekuensi, penyuluhan, kondisi lingkungan pertanian, status petani; serta motivasi petani membudidayakan gandum. Hasil utama penelitian ini memiliki implikasi penting bagi para pembuat kebijakan sehubungan dengan mempromosikan budidaya gandum di Indonesia.

\section{METODE PENELITIAN}

Survei dilakukan di 3(tiga) lokasi yang melakukan kegiatan pengenalan budidaya gandum, yaitu Dusun Gatak, Desa Tlogoweru, Kecamatan Guntur, Kabupaten Demak; Dusun Margomulyo, Desa Ngadirojo, Kecamatan Ampel, Kabupaten Boyolali; dan Dusun Bendo Tali, Desa Sumberejo, Kecamatan Klaten Selatan, Kabupaten Klaten. Kondisi geografi tiap wilayah sebagai berikut: wilayah Demak sekitar $800 \mathrm{~m}$ di atas permukaan laut, didominasi oleh penanaman padi, wilayah Boyolali sekitar 1200 $\mathrm{m}$ di atas permukaan laut yang didominasi oleh pertanian tembakau, dan wilayah Klaten sekitar $400 \mathrm{~m}$ di atas permukaan laut yang didominasi oleh pertanian padi.

Di Kabupaten Boyolali, proses budidaya gandum dilakukan pada tahun 2017 dengan menanam tanaman gandum di area seluas $1500 \mathrm{~m}^{2}$ dengan menerapkan sistem tumpangsari dengan

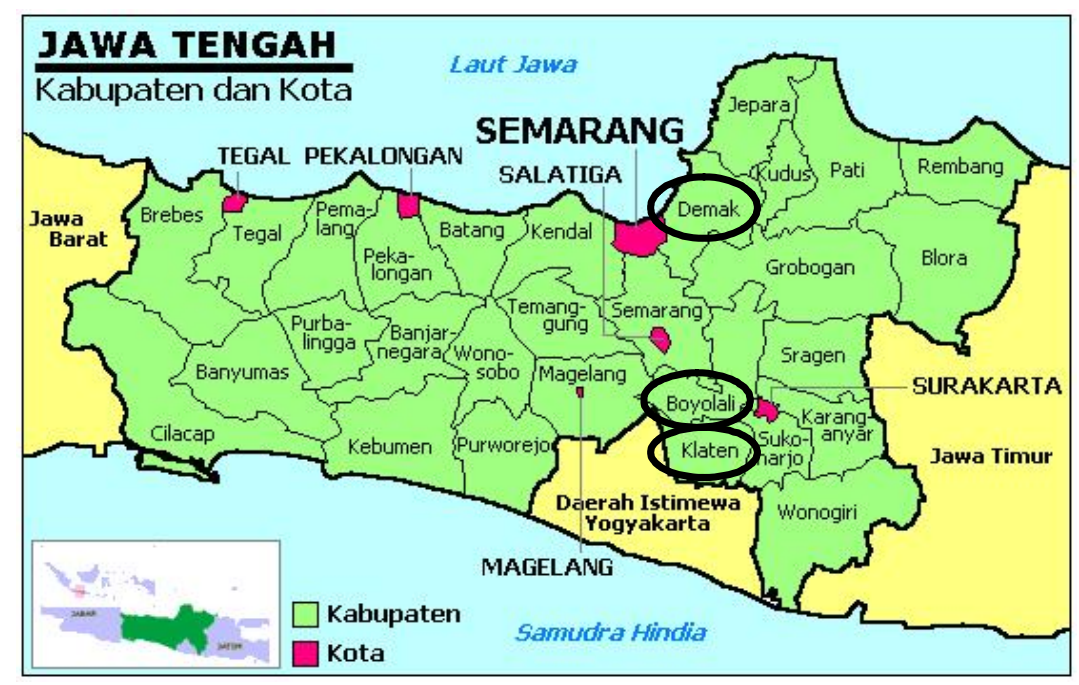

Gambar 1 Lokasi Penelitian di Kabupaten Klaten, Demak, dan Boyolali 
tanaman tembakau, yang merupakan tanaman utama petani di Kabupaten Boyolali. Di Kabupaten Demak dan Klaten, gandum ditanam di lahan seluas $500 \mathrm{~m}^{2}$, dimana petani di Demak dan Klaten bermatapencaharian sebagai petani padi.

Penentuan responden menggunakan teknik sensus dan prosedur ini menghasilkan total responden yakni 30 petani terdiri dari 14 petani dari Kabupaten Boyolali, 6 petani Kabupaten Demak, dan 10 petani Kabupaten Klaten. Pengambilan data menggunakan Teknik survei yang dilakukan dengan menggunakan panduan kuesioner selama Mei hingga Desember 2018.

Alur berpikir penelitian dapat digambarkan sebagai berikut:

$$
\rho=1-\frac{6 \sum \mathrm{bi}^{2}}{\mathrm{n}\left(\mathrm{n}^{2}-1\right)}
$$

dimana

ñ: koefisien korelasi Rank Spearman

bi: perbedaan antara peringkat variabel

n: jumlah sampel

\section{HASIL DAN PEMBAHASAN}

\section{Karakteristik Petani}

Karaketristik petani meliputi gender, usia petani, pendidikan petani, status penguasaan lahan, pengalaman berusahatani, luas lahan yang dimiliki, dan frekuensi mendapatkan ditampilkan pada Tabel 1.

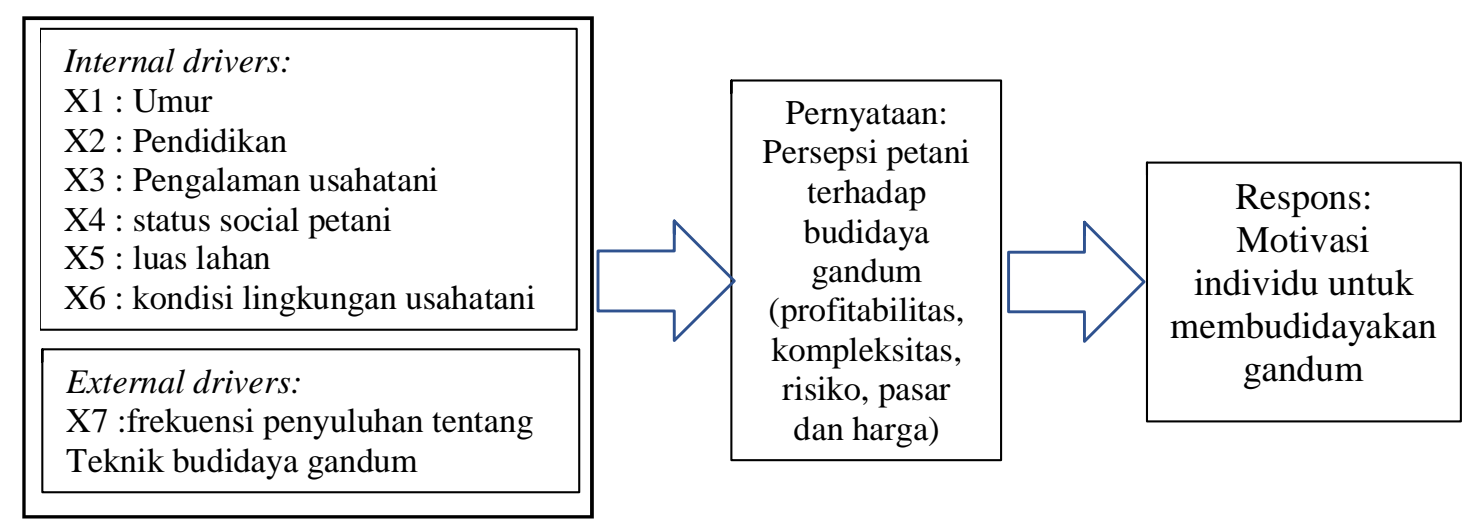

Gambar 2 Alur Pikir Penelitian (internal dan external drivers berkaitan secara langsung persepsi petani dan persepsi petani mempengaruhi motivasi untuk membudidayakan gandum)

Instrumen penelitian diuji reliabilitas dan validitasnya, yakni intrumen untuk mengukur kondisi lingkungan, persepsi petani, dan motivasi petani.Teknik analisis data menggunakan analisis korelasi rank Spearman dengan tingkat $0,05 \%$. Rumus korelasi peringkat Spearman (Rank Spearman) adalah sebagai berikut:
Petani yang terlibat dalam kegiatan pengenalan budidaya gandum didominasi laki-laki. Tabel 1 juga menunjukkan bahwa usia rata-rata responden di Kabupaten Demak, Boyolali dan Klaten berada dalam kisaran usia 41-50. Hal ini menunjukkan bahwa rata-rata responden adalah responden berusia produktif dan telah lama berkecimpung di dunia pertanian. 
Tabel 1 Karakteristik Petani Responden

\begin{tabular}{|c|c|c|c|c|c|c|c|}
\hline \multirow{2}{*}{ Karakteristik } & \multirow{2}{*}{ Kategori } & \multicolumn{2}{|c|}{ Demak } & \multicolumn{2}{|c|}{ Boyolali } & \multicolumn{2}{|c|}{ Klaten } \\
\hline & & Total & $(\%)$ & Total & $(\%)$ & Total & $(\%)$ \\
\hline \multirow[t]{2}{*}{ Gender } & Laki-laki & 3 & 50 & 8 & 57,15 & 6 & 60 \\
\hline & Perempuan & 3 & 50 & 6 & 42,85 & 4 & 40 \\
\hline \multicolumn{2}{|l|}{ Total } & 6 & 100 & 14 & 100 & 10 & 100 \\
\hline \multirow[t]{4}{*}{ Usia (tahun) } & $20-30$ & 1 & 16,67 & 2 & 14,29 & 2 & 20 \\
\hline & $31-40$ & 2 & 33,33 & 4 & 28,57 & 1 & 10 \\
\hline & $41-50$ & 3 & 50,00 & 5 & 35,71 & 4 & 40 \\
\hline & $>50$ & 0 & - & 3 & 21,43 & 3 & 30 \\
\hline \multicolumn{2}{|l|}{ Total } & 6 & 100 & 14 & 100 & 10 & 100 \\
\hline \multirow[t]{5}{*}{ Pendidikan } & $\begin{array}{l}\text { Sekolah } \\
\text { Dasar }\end{array}$ & 5 & 83,33 & 12 & 85,72 & 8 & 80 \\
\hline & SMP & 1 & 16,67 & 1 & 7,14 & 2 & 20 \\
\hline & SMA & 0 & 0 & 0 & 0 & 0 & 0 \\
\hline & $\begin{array}{l}\text { Perguruan } \\
\text { tinggi }\end{array}$ & 0 & 0 & 1 & 7,14 & 0 & 0 \\
\hline & \multicolumn{7}{|c|}{ Total } \\
\hline \multirow{2}{*}{$\begin{array}{l}\text { Status } \\
\text { penguasaan } \\
\text { lahan } \\
\end{array}$} & Pemilik & 6 & 100 & 14 & 100 & 1 & 10 \\
\hline & $\begin{array}{l}\text { Tenaga } \\
\text { kerja }\end{array}$ & 0 & 0 & 0 & 0 & 9 & 90 \\
\hline \multicolumn{2}{|l|}{ Total } & 6 & 100 & 14 & 100 & 10 & 100 \\
\hline \multirow{4}{*}{$\begin{array}{l}\text { Pengalaman } \\
\text { berusahatani } \\
\text { (tahun) }\end{array}$} & $<10$ & 0 & 0 & 2 & 14,29 & 2 & 20 \\
\hline & $10-20$ & 4 & 66,67 & 4 & 28,56 & 0 & 0 \\
\hline & $30-40$ & 2 & 33,33 & 6 & 42,86 & 5 & 50 \\
\hline & $>40$ & - & - & 2 & 14,29 & 3 & 30 \\
\hline \multicolumn{2}{|l|}{ Total } & 6 & 100 & 14 & 100 & 10 & 100 \\
\hline \multirow{4}{*}{ Luas lahan } & $<1$ ha & 4 & 66,67 & 2 & 14,29 & 1 & 10 \\
\hline & $1-2$ ha & 2 & 33,33 & 11 & 78,57 & 0 & 0 \\
\hline & $>2$ ha & 0 & 0 & 1 & 7,14 & 0 & 0 \\
\hline & $\begin{array}{l}\text { Tidak ada } \\
\text { lahan }\end{array}$ & 0 & 0 & 0 & 0 & 9 & 90 \\
\hline \multicolumn{2}{|l|}{ Total } & 6 & 100 & 14 & 100 & 10 & 100 \\
\hline \multirow{3}{*}{$\begin{array}{l}\text { Frekuensi } \\
\text { mendapatkan } \\
\text { penyuluhan } \\
\text { tentang } \\
\text { budidaya } \\
\text { gandum }\end{array}$} & $<3$ kali & 5 & 83,33 & 6 & 42,86 & 9 & 90 \\
\hline & $3-5$ kali & - & - & 6 & 42,86 & - & - \\
\hline & $>5$ kali & 1 & 16,67 & 2 & 14,29 & 1 & 10 \\
\hline \multicolumn{2}{|l|}{ Total } & 6 & 100 & 14 & 100 & 10 & 100 \\
\hline
\end{tabular}

Sumber: analisis data primer (2019)

Mayoritas responden adalah petani dengan tingkat pendidikan dasar. Rendahnya tingkat pendidikan karena di wilayah tersebut, karena masyarakat petani turun menurun kurang memandang penting jenjang pendidikan. Mayoritas responden di Boyolali telah berpengalaman dalam bertani selama 30-40 tahun, sedangkan di Demak petani padi didominasi oleh lama pengalaman 10-20 tahun dan di Klaten didominasi oleh lama pengalaman 3040 tahun. Di tiga wilayah penelitian, terbukti bahwa mata pencaharian pertanian merupakan mata pencaharian utama sejak lama.

Fenomena bahwa petani di negara kita merupakan petani lahan sempit, tertangkap di 
penelitian ini. Mayoritas petani di Demak memiliki luas lahan kurang dari 1 ha. Dominasi luas lahan di Boyolali adalah di lahan 1-2 ha dengan frekuensi 78,57\%, dan hampir seluruh petani responden Klaten tidak memiliki lahan pertanian. Di Klaten, diketahui bahwa hanya $10 \%$ dari area pertanian memiliki luas $<1$ ha, dengan $90 \%$ sisanya petani tidak memiliki tanah secara pribadi, tetapi hanya sebagai buruh tani. Luas tanah rata-rata di Klaten adalah $\pm 0,025$ ha. Hasil ini menunjukkan bahwa luas lahan pertanian di ketiga wilayah tersebut didominasi oleh luas <1 ha dan pada luas 1-2 ha. Fenomena penyempitan lahan sawah di Klaten sesuai dengan yang didapatkan dalam penelitian Nugroho dkk (2017) bahwa di Kabupaten Klaten terjadi perubahan penggunaan lahan sawah ke non sawah mengalami peningkatan selama 2004 sampai 2014.

Mayoritas responden di Demak dan Klaten menghadiri sosialisasi budidaya gandum di bawah 3 kali, sementara mayoritas responden di Kabupaten Boyolali memiliki 3 - 5 kali perluasan budidaya gandum. Pembimbingan budidaya di Boyolali oleh narasumber lebih aktif, sedangkan di Kabupaten Demak dan Klaten metode introduksi melalui penyuluhan umum dilanjutkan dengan koordinasi terbatas pada koordinator di masing-masing daerah yang selanjutnya.

Persepsi petani tentang kecocokan kondisi lingkungan untuk budidaya gandum ditampilkan pada Tabel 2.

Berdasarkan Tabel 2, terlihat bahwa petani di Kabupaten Boyolali cenderung menganggap kondisi lingkungan yang cocok untuk budidaya gandum, sedangkan responden di Kabupaten Klaten dan Kabupaten Demak cenderung berpikir bahwa kondisi lingkungan tidak cocok untuk budidaya gandum. Petani tembakau di Boyolali memiliki persepsi yang lebih tinggi terhadap kecocokan lingkungan terhadap budidaya gandum antara lain dipengaruhi oleh

Tabel 2 Persepsi Petani Kecocokan Kondisi Lingkungan Usahatani bagi Budidaya Gandum

\begin{tabular}{|c|c|c|c|c|c|c|c|c|c|c|c|}
\hline \multirow[t]{2}{*}{ Boyolali } & \multicolumn{2}{|c|}{ Sangat setuju } & \multicolumn{2}{|c|}{ Setuju } & \multicolumn{2}{|c|}{ Neutral } & \multicolumn{2}{|c|}{ Tidak setuju } & \multicolumn{2}{|c|}{$\begin{array}{c}\text { Sangat tidak } \\
\text { setuju }\end{array}$} & \multirow{2}{*}{$\begin{array}{l}\text { Total } \\
\text { Freq } \\
\end{array}$} \\
\hline & Freq. & $\%$ & Freq. & $\%$ & Freq & $\%$ & Freq. & $\%$ & Freq. & $\%$ & \\
\hline Tanah & 2 & 14.29 & 4 & 28.57 & 5 & 35.71 & 3 & 21.43 & - & - & 100 \\
\hline Suhu & 2 & 14.29 & 6 & 42.85 & 3 & 21.43 & 3 & 21.43 & - & - & 100 \\
\hline Curah Hujan & - & - & 2 & 14.29 & 3 & 21.43 & 9 & 64.28 & - & - & 100 \\
\hline Penyinaran & 2 & 14.29 & 5 & 35.71 & 5 & 35.71 & 2 & 14.29 & - & - & 100 \\
\hline \multirow[t]{2}{*}{ Klaten } & \multicolumn{2}{|c|}{ Sangat setuju } & \multicolumn{2}{|c|}{ Setuju } & \multicolumn{2}{|c|}{ Neutral } & \multicolumn{2}{|c|}{ Tidak setuju } & \multicolumn{2}{|c|}{$\begin{array}{c}\text { Sangat tidak } \\
\text { setuju }\end{array}$} & Total \\
\hline & Freq. & $\%$ & Freq. & $\%$ & Freq & $\%$ & Freq. & $\%$ & Freq. & $\%$ & Freq \\
\hline Tanah & - & - & 2 & 20 & 4 & 40 & 4 & 40 & -1 & - & 100 \\
\hline Suhu & - & - & - & - & 2 & 20 & 6 & 60 & 2 & 20 & 100 \\
\hline Curah Hujan & - & - & - & - & 4 & 40 & 5 & 50 & 1 & 10 & 100 \\
\hline Penyinaran & - & - & - & - & 4 & 40 & 6 & 60 & - & - & 100 \\
\hline \multirow[t]{2}{*}{ Demak } & \multicolumn{2}{|c|}{ Sangat setuju } & \multicolumn{2}{|c|}{ Setuju } & \multicolumn{2}{|c|}{ Neutral } & \multicolumn{2}{|c|}{ Tidak setuju } & \multicolumn{2}{|c|}{$\begin{array}{c}\text { Sangat tidak } \\
\text { setuju }\end{array}$} & Total \\
\hline & Freq. & $\%$ & Freq. & $\%$ & Freq & $\%$ & Freq. & $\%$ & Freq. & $\%$ & Freq \\
\hline Tanah & 1 & 16.67 & 1 & 16.67 & 1 & 16.66 & 2 & 33.33 & 1 & 16.67 & 100 \\
\hline Suhu & - & - & - & - & 3 & 50 & 2 & 33.33 & 1 & 16.67 & 100 \\
\hline Curah Hujan & - & - & - & - & 2 & 33.34 & 2 & 33.33 & 2 & 33.33 & 100 \\
\hline Penyinaran & - & - & 1 & 16.67 & 2 & 33.33 & - & 50 & - & - & 100 \\
\hline
\end{tabular}

Sumber: analisis data primer (2019) 
pemahaman petani tentang syarat tumbuh budidaya gandum yang diterima dari penyuluh dengan pemahaman kondisi lingkungan di wilayah pertaniannya. Pemahaman yang baik tentang syarat tumbuh gandum dipengaruhi metode sosialisasi dan penyuluhan yang dilakukan, seperti disimpulkan penelitian Zulvera (2014) dan Sugiarta dkk (2017) yang menyatakan bahwa ketepatan metode, kesesuaian materi, kesesuaian model komunikasi, kompetensi penyuluh dan frekuensi penyuluhan ternyata berhubungan secara positif dengan perilaku dan pengetahuan petani.

\section{Persepsi Petani tentang Budidaya Gandum}

Persepsi petani tentang budidaya gandum diukur dari beberapa kategori, termasuk budidaya gandum menguntungkan, budidaya gandum mudah, budidaya gandum memiliki risiko kegagalan panen rendah dan budidaya gandum memiliki harga jual yang tinggi.

Tabel 3 menunjukkan bahwa di Kabupaten Boyolali, mayoritas petani menjawab netral dengan persentase $42,86 \%$ untuk pernyataan bahwa menanam gandum menguntungkan, sementara hanya $7,15 \%$ responden jawab tidak setuju. Jawaban netral menunjukkan petani masih ragu-ragu dengan potensi usahatani gandum dalam menghasilkan keuntungan. Pasar gandum belum banyak diketahui oleh petani, oleh karena itu jawaban petani cenderung ragu. Dalam kategori budidaya mudah, responden menjawab masing-masing dengan persentase $35,71 \%$ untuk jawaban yang disetujui dan netral, sebanyak 14,29\% menjawab sangat setuju dan tidak setuju. Persepsi petani terhadap kemudahan budidaya gandum

Tabel 3 Persepsi Petani

\begin{tabular}{|c|c|c|c|c|c|c|c|c|c|c|}
\hline \multirow[t]{2}{*}{ Boyolali } & \multicolumn{2}{|c|}{ Sangat setuju } & \multicolumn{2}{|c|}{ Setuju } & \multicolumn{2}{|c|}{ Neutral } & \multicolumn{2}{|c|}{ Tidak setuju } & \multicolumn{2}{|c|}{$\begin{array}{c}\text { Sangat tidak } \\
\text { setuju }\end{array}$} \\
\hline & Frek. & $\%$ & Frek. & $\%$ & Frek. & $\%$ & Frek. & $\%$ & Frek. & $\%$. \\
\hline Keuntungan & 2 & 14.29 & 5 & 35.71 & 6 & 42.86 & 1 & 7.15 & - & - \\
\hline Kerumitan & 2 & 14.29 & 5 & 35.71 & 5 & 35.71 & 2 & 14.29 & - & - \\
\hline Resiko & - & - & 2 & 14.28 & 6 & 42.86 & 6 & 42.86 & - & - \\
\hline Harga & - & - & 7 & 50 & 7 & 50 & - & - & - & \\
\hline \multirow[t]{2}{*}{ Klaten } & \multicolumn{2}{|c|}{ Sangat setuju } & \multicolumn{2}{|c|}{ Setuju } & \multicolumn{2}{|c|}{ Neutral } & \multicolumn{2}{|c|}{ Tidak setuju } & \multicolumn{2}{|c|}{$\begin{array}{c}\text { Sangat tidak } \\
\text { setuju }\end{array}$} \\
\hline & Frek. & $\%$ & Frek. & $\%$ & Frek. & $\%$ & Frek & $\%$ & Frek & $\%$ \\
\hline Keuntungan & - & - & - & - & 1 & 10 & 6 & 60 & 3 & 30 \\
\hline Kerumitan & - & - & 2 & 20 & 4 & 40 & 2 & 20 & 2 & 20 \\
\hline Resiko & - & - & - & - & - & - & 5 & 50 & 5 & 50 \\
\hline Harga & - & - & 4 & 40 & 3 & 30 & 3 & 30 & - & - \\
\hline \multirow[t]{2}{*}{ Demak } & \multicolumn{2}{|c|}{ Sangat setuju } & \multicolumn{2}{|c|}{ Setuju } & \multicolumn{2}{|c|}{ Neutral } & \multicolumn{2}{|c|}{ Tidak setuju } & \multicolumn{2}{|c|}{$\begin{array}{c}\text { Sangat tidak } \\
\text { setuju }\end{array}$} \\
\hline & Frek. & $\%$ & Frek. & $\%$ & Frek. & $\%$ & Frek. & $\%$ & Frek. & $\%$ \\
\hline Keuntungan & - & - & - & - & 1 & 16.67 & 2 & 33.33 & 3 & 50 \\
\hline Kerumitan & - & - & 1 & 16.67 & 1 & 16.66 & 3 & 50 & 1 & 16.67 \\
\hline Resiko & - & - & - & - & 1 & 16.67 & 4 & 66.66 & 1 & 16.67 \\
\hline Harga & - & - & 2 & 33.33 & 3 & 50 & 1 & 16.67 & - & - \\
\hline
\end{tabular}

Source: analisis data primer (2019) 
cenderung rendah, artinya masih cukup banyak petani menganggap budidaya gandum sulit tidak semudah usahatani tembakau yang telah mereka lakukan sejak lama. Dalam kategori risiko kegagalan panen rendah, 42,86\% responden menjawab netral dan tidak setuju, sisanya menjawab setuju dengan persentase 14,29\%. Dalam kategori harga jual tinggi, responden menjawab hal yang sama pada pilihan jawaban setuju dan netral dengan masing-masing 50\%. Distribusi jawaban petani di Boyolali dipengaruhi oleh kondisi yang petani alami selama budidaya tembakau. Risiko dalam bertanam tembakau dapat dikatakan tinggi, seperti yang didapatkan dalam penelitian Ihsannudin (2010), bahwa sebagian besar petani yang melakukan usahatani tembakau jenis Temanggung maupun jenis Muntilan mengalami kerugian karena pengaruh iklim. Risiko yang dihadapi petani tembakau, meliputi risiko produksi yang dipengaruhi cuaca, risiko fluktuasi harga jual, dan risiko pendapatan.

Di Kabupaten Klaten, mayoritas petani menjawab bahwa mereka tidak setuju dengan persentase $60 \%$ untuk pernyataan bahwa penanaman gandum menguntungkan, sementara $30 \%$ lainnya menjawab sangat tidak setuju. Dalam kategori kemudahan budidaya, responden menjawab $40 \%$ netral, $20 \%$ setuju, $20 \%$ tidak setuju dan $20 \%$ sisanya sangat tidak setuju. Sedangkan pada risiko kegagalan panen yang rendah, masing-masing 50\% menjawab tidak setuju dan sangat tidak setuju. Dalam kategori harga jual tinggi, responden menjawab setuju sebanyak $40 \%$, sisanya $30 \%$ menjawab netral dan 30\% tidak setuju. Distribusi jawaban petani padi Klaten terhadap budidaya gandum yang ditampilkan di Tabel3, dipengaruhi dengan pengalaman dan kondisi usahatani padi yang dihadapi petani. Pengalaman yang lama dalam berusahatani padi menghasilkan suatu penyimpulan bahwa budidaya padi dianggap tidak rumit dan lebih menguntungkan dibandingkan budidaya gandum. Di sisi lain, petani menganggap usahatani padi memiliki risiko yang rendah, seperti yang diungkapkan dalam penelitian Fauziyah (2011) menyatakan tingkat risiko produktivitas, biaya, dan pendapatan usahatani padi termasuk dalam kategori rendah.

Di Kabupaten Demak, mayoritas petani menjawab sangat tidak setuju dengan persentase $50 \%$ untuk pernyataan bahwa penanaman gandum menguntungkan, sedangkan 33,33\% dalam kategori kemudahan budidaya, responden menjawab tidak setuju, 16,67\% menjawab netral. Sementara dalam kategori risiko gagal panen rendah, $66,66 \%$ responden menjawab tidak setuju, sisanya $16,67 \%$ menjawab sangat tidak setuju dan $16,67 \%$ menjawab netral. Dalam kategori harga jual tinggi, responden menjawab netral sebanyak 50\%, 33\% lainnya setuju, sedangkan $16,67 \%$ responden lain menjawab tidak setuju. Persepsi petani padi di Demak terhadap budidaya gandum yang cenderung meragukan capaian keuntungan, kemudahan budidaya, dan harga jual yang kurang menguntungkan seperti pada Tabel 3, dipengaruhi oleh pengalaman usahatani yang lama dan pendekatan introduksi yang dilakukan oleh penyuluh atau pemberi program. Pendekatan introduksi yang kurang intensif mempengaruhi pengetahuan dan sikap petani terhadap teknologi yang diintroduksikan. Frekuensi penyuluhan yang relatif jarang 
menyebabkan informasi yang lengkap dan rinci diterima petani dalam kapasitas yang terbatas.

\section{Motivasi Petani untuk Membudidayakan} Gandum

Tabel 4 menunjukkan bahwa motivasi individu petani untuk membudidayakan gandum, di Boyolali didorong olehmotivasi ekonomi, sosial dan ekologi yang tinggi, yang masing-masing berkisar antara 50\%, 57,14\% dan 50\%. Sementara di Klaten, motivasi yang mendorong petani untuk menanam tanaman alternatif adalah tinggi dalam kategori motivasi ekonomi dan sosial, yang masing-masing adalah $60 \%$ dan $50 \%$, sedangkan motivasi ekologis netral adalah 60\%. Di Demak 50\% responden menjawab netral untuk pilihan motivasi ekonomi, dan dalam kategori motivasi sosial dan ekologis rendah, yang masing-masing dalam persentase $50 \%$.
Menurut hasil survei, petani di Boyolali dan Demak lebih suka menanam gandum karena alasan ekonomi dan sosial, sedangkan petani Klaten termotivasi membudidayakan gandum terlebih karena motivasi ekonomi. Survei menemukan bahwa petani di 3 kabupaten tersebut termotivasi menanan gandum, artinya hal ini menjadi peluang yang baik untuk melakukan program diversifikasi tanaman selain tanaman yang biasa ditanam petani. Teknologi baru diharapkan menjadi sesuatu yang menarik bagi petani untuk diujicoba lebih lanjut.

\section{Hasil Analisis Korelasi}

Tabel 5 menunjukkan hasil analisis korelasi antara faktor internal dan faktor eksternal dengan persepsi petani, dan korelasi antara persepsi petani dan motivasi petani untuk membudidayakan gandum.

Tabel 4 Motivasi Individual Petani untuk Membudidayakan Gandum

\begin{tabular}{|c|c|c|c|c|c|c|c|c|c|c|c|}
\hline \multirow[t]{2}{*}{ Boyolali } & \multicolumn{2}{|c|}{ Sangat setuju } & \multicolumn{2}{|c|}{ Setuju } & \multicolumn{2}{|c|}{ Neutral } & \multicolumn{2}{|c|}{ Tidak setuju } & \multicolumn{2}{|c|}{$\begin{array}{c}\text { Sangat tidak } \\
\text { setuju }\end{array}$} & \multirow{2}{*}{$\begin{array}{c}\text { Total } \\
\%\end{array}$} \\
\hline & Frek. & $\%$ & Frek. & $\%$ & Frek. & $\%$ & Frek. & $\%$ & Frek. & $\%$ & \\
\hline Ekonomi & 3 & 21.43 & 8 & 57.14 & 3 & 21.43 & - & - & - & - & 100 \\
\hline Sosial & 2 & 14.29 & 9 & 64.29 & 2 & 14.29 & 1 & 7.14 & - & - & 100 \\
\hline Ekologi & 1 & 7.14 & 8 & 57.14 & 4 & 28.57 & 1 & 7.14 & - & - & 100 \\
\hline \multirow[t]{2}{*}{ Klaten } & \multicolumn{2}{|c|}{ Sangat setuju } & \multicolumn{2}{|c|}{ Setuju } & \multicolumn{2}{|c|}{ Neutral } & \multicolumn{2}{|c|}{ Tidak setuju } & \multicolumn{2}{|c|}{$\begin{array}{l}\text { Sangat tidak } \\
\text { setuju }\end{array}$} & Total \\
\hline & Frek. & $\%$ & Frek. & $\%$ & Frek. & $\%$ & Frek. & $\%$ & Frek. & $\%$ & Frek. \\
\hline Ekonomi & - & - & 6 & 60 & 4 & 40 & - & - & - & - & 100 \\
\hline Sosial & 1 & 10 & 5 & 50 & 4 & 40 & - & - & - & - & 100 \\
\hline Ekologi & - & - & 4 & 40 & 6 & 60 & - & - & - & - & 100 \\
\hline \multirow[t]{2}{*}{ Demak } & \multicolumn{2}{|c|}{ Sangat setuju } & \multicolumn{2}{|c|}{ Setuju } & \multicolumn{2}{|c|}{ Neutral } & \multicolumn{2}{|c|}{ Tidak setuju } & \multicolumn{2}{|c|}{$\begin{array}{c}\text { Sangat tidak } \\
\text { setuju }\end{array}$} & Total \\
\hline & Frek. & $\%$ & Frek. & $\%$ & Frek. & $\%$ & Frek. & $\%$ & Frek. & $\%$ & Frek. \\
\hline Ekonomi & 2 & 33.33 & 1 & 16.67 & 3 & 50 & - & - & - & - & 100 \\
\hline Sosial & 1 & 16.67 & 2 & 33.33 & - & - & 3 & 50 & - & - & 100 \\
\hline Ekologi & - & - & 3 & 50 & - & - & 3 & 50 & - & - & 100 \\
\hline
\end{tabular}

Source: analisis data primer (2019) 
Tabel 5 Analisis Korelasi Persepsi petani tentang Budidaya Gandum dengan Karakteristik dan Motivasi Petani

\begin{tabular}{llcccc}
\hline No & Variable & Sig $<0.05$ & Rs & Keputusan & $\begin{array}{c}\text { Tingkat } \\
\text { Hubungan }\end{array}$ \\
\hline 1. & Umur $\left(\mathrm{X}_{1}\right)$ & 0,718 & $-0,069$ & Tidak signifikan & Sangat lemah \\
2. & Pendidikan $\left(\mathrm{X}_{2}\right)$ & 0,891 & $-0,026$ & Tidak signifikan & Sangat lemah \\
3. & $\begin{array}{l}\text { Pengalaman bertani } \\
\left(\mathrm{X}_{3}\right)\end{array}$ & 0,900 & $-0,024$ & Tidak signifikan & Sangat lemah \\
4. & Status petani $\left(\mathrm{X}_{4}\right)$ & 0,001 & $0,559^{* *}$ & Sangat signifikan & Kuat \\
6. & $\begin{array}{l}\text { Luas kepemilikan } \\
\text { lahan }\left(\mathrm{X}_{5}\right)\end{array}$ & 0,000 & $0,751^{* *}$ & $\begin{array}{c}\text { Sangat } \\
\text { Signifikan }\end{array}$ & Kuat \\
7. & $\begin{array}{l}\text { Frekuensi penyuluhan } \\
\text { tentang gandum }\left(\mathrm{X}_{6}\right)\end{array}$ & 0,127 & 0,285 & Tidak signifikan & Sedang \\
8. $\quad \begin{array}{l}\text { Kondisi lingkungan } \\
\text { pertaniuan }\left(\mathrm{X}_{7}\right)\end{array}$ & 0,108 & 0,299 & Tidak signifikan & Sedang \\
9otivasi untuk & membudidayakan & 0,015 & $0,440^{*}$ & Signifikan & Sedang \\
\hline
\end{tabular}

Keterangan: *signifikan pada level kepercayaan 5\%

Tabel 5 menunjukkan variabel umur $\left(\mathrm{X}_{1}\right)$ memiliki nilai signifikansi 0,718 dimana variabel tersebut dinyatakan berkorelasi jika nilainya $<0,05$, sehingga dapat dikatakan bahwa variabel $\mathrm{X}_{1}$ tidak signifikan berkorelasi dengan persepsi petani dalam budidaya gandum. Nilai koefisien korelasi berada pada -0,069, dimana nilai ini berarti bahwa variabel tersebut memiliki hubungan korelasi yang sangat lemah dengan Y. Arah korelasi antara variabel $\mathrm{X}_{1}$ dan persepsi petani (Y) negatif, ini menunjukkan bahwa hubungan antara usia dan Persepsi petani tidak searah, artinya semakin tinggi atau rendahnya nilai variabel umur tidak berkaitan dalam meningkatkan atau menurunkan persepsi petani tentang budidaya gandum. Hasil ini berbanding terbalik dengan penelitian sebelumnya dari Sam et al (2018) dan Ansari et al (2018), bahwa usia ditemukan berhubungan signifikan dengan persepsi petani. Ini mungkin karena budidaya gandum masih relatif baru di Indonesia, terutama di Jawa Tengah, berbeda dengan budidaya lainnya dan teknik pertanian organik yang sudah akrab diusahakan oleh petani, sehingga hasil persepsi berbeda dan tidak berkorelasi antara usia petani. dan persepsi petani tentang budidaya gandum.

Variabel pendidikan $\left(\mathrm{X}_{2}\right)$ memiliki nilai signifikansi 0,891, dimana nilai ini> 0,05 sehingga variabel $\mathrm{X}_{2}$ tidak berkorelasi signifikan dengan persepsi petani dalam budidaya gandum (Y). Nilai koefisien korelasi pada variabel $\mathrm{X}_{2}$ adalah pada nilai -0,026, di mana nilai dalam kisaran ini diklasifikasikan dalam kategori korelasi yang sangat lemah. Arah korelasi antara variabel $\mathrm{X}_{2}$ dan $\mathrm{Y}$ adalah negatif, sehingga kenaikan atau penurunan nilai variabel $\mathrm{X}_{2}$ tidak dalam arah yang sama dengan penurunan atau peningkatan Y. Hasil ini berbanding lurus dengan penelitian sebelumnya yang dilakukan oleh Wijayanti et al (2015) bahwa variabel pendidikan tidak secara signifikan mempengaruhi respon persepsi petani dengan adanya inovasi budidaya sorgum. Sebaliknya, Ansari et al (2018) 
menemukan bahwa pendidikan secara signifikan terkait dengan persepsi petani. Hasil ini diduga karena budidaya gandum yang masih baru di Indonesia, terutama di Jawa Tengah, sehingga petani masih tidak tahu secara dekat tentang budidaya gandum, dan tingkat pendidikan tidak berkorelasi dalam hal persepsi petani.

Variabel pengalaman bertani $\left(\mathrm{X}_{3}\right)$ memiliki nilai signifikansi 0,900, dimana nilai ini> 0,05, sehingga dapat disimpulkan bahwa variabel pengalaman bertani tidak berkorelasi signifikan dengan persepsi petani terhadap budidaya gandum (Y). Nilai koefisien korelasi berada pada-0,024, di mana nilai ini termasuk dalam kategori hubungan korelasi yang sangat lemah. Arah korelasi variabel $\mathrm{X}_{3}$ juga tidak sejalan dengan persepsi petani (Y). Sehingga peningkatan atau penurunan $\mathrm{X}_{3}$ tidak terkait dengan peningkatan atau penurunan $\mathrm{Y}$. Temuan serupa ditemukan dalam penelitian sebelumnya oleh Widiyastuti et al (2016), bahwa durasi pengalaman bertani tidak mempengaruhi petani. persepsi pengembangan sistem SRI, tetapi Ansari et al (2018) menemukan bahwa pengalaman bertani berhubungan secara signifikan dengan persepsi petani. Pengalaman bertani dalam penelitian ini adalah pengalaman bertani tanaman asli (padi dan tembakau) yang memiliki karakteristik persyaratan tumbuh dan cara budidaya yang sangat berbeda dengan budidaya gandum, sehingga sangat realistis jika pengalaman bertani tidak berhubungan. dengan persepsi petani mengolah gandum.

Variabel status petani $\left(\mathrm{X}_{4}\right)$, diketahui memiliki nilai signifikansi 0,001, dimana nilai ini $<0,05$ sehingga dapat dikatakan bahwa variabel $\mathrm{X}_{4}$ berkorelasi sangat signifikan terhadap persepsi petani dalam budidaya gandum (Y). Nilai koefisien korelasi untuk variabel $\mathrm{X}_{4}$ adalah $0,559 * *$, nilai dalam rentang ini menunjukkan korelasi antara $\mathrm{X}_{4}$ dan $\mathrm{Y}$ dalam kategori kuat. Arah korelasi antara variabel $\mathrm{X}_{4}$ dan $\mathrm{Y}$ adalah positif, sehingga kenaikan atau penurunan nilai pada variabel $\mathrm{X}_{4}$ sejalan dengan penurunan atau peningkatan Y. Hasil ini diduga karena peningkatan kepemilikan tanah oleh petani juga meningkatkan persepsi untuk menanam gandum.

Luas lahan $\left(\mathrm{X}_{5}\right)$ memiliki nilai signifikansi 0,000, dimana nilai ini lebih dari $<0,05$, sehingga dapat diartikan bahwa variabel $\mathrm{X}_{6}$ memiliki korelasi yang sangat signifikan terhadap persepsi petani dalam budidaya gandum(Y). Koefisien korelasi pada variabel $\mathrm{X}_{5}$ ini adalah 0,751 , di mana dalam kisaran ini korelasi memiliki korelasi yang kuat. Arah korelasi antara variabel $\mathrm{X}_{6}$ dan $\mathrm{Y}$ menunjukkan nilai positif, sehingga semakin tinggi variabel $\mathrm{X}_{6}$ juga akan meningkatkan nilai Y. Hasil ini berbanding terbalik dengan penelitian Wijayanti et al (2015) bahwa variabel luas lahan memiliki tidak ada pengaruh yang signifikan terhadap persepsi atau respons petani terhadap inovasi budidaya akuakultur. Rogers (1995) menyatakan bahwa petani yang lebih besar cenderung mengadopsi teknologi baru sebelumnya.

Frekuensi ekstensi $\left(\mathrm{X}_{6}\right)$ memilikinilai signifikansi 0,127 , dimana nilai ini $>0,05$, sehingga dapat diartikan bahwa variabel $\mathrm{X}_{7}$ tidak berkorelasi signifikan dengan persepsi petani dalam budidaya gandum (Y). Nilai koefisien korelasi pada variabel $\mathrm{X}_{7}$ ini adalah 0,285 , dimana pada rentang nilai 0,26 - 0,50 adalah nilai koefisien korelasi dengan indikator korelasi yang cukup. 
Arah korelasi antara variabel $\mathrm{X}_{7}$ dan $\mathrm{Y}$ menunjukkan nilai positif, sehingga semakin tinggi variabel $\mathrm{X}_{7}$ juga akan meningkatkan nilai Y. Hasil ini berbanding lurus dengan hasil penelitian Ginting et al (2011) bahwa intensitas ekstensi pertanian tidak berpengaruh pada persepsi petani tentang inovasi teknologi.

Variabel kondisi lingkungan pertanian $\left(\mathrm{X}_{7}\right)$ memiliki nilai signifikansi 0,108 , dimananilai ini> 0,05 , sehingga dapat diartikan bahwa variabel $\mathrm{X}_{7}$ tidak berkorelasi signifikan dengan persepsi petani dalam budidaya gandum (Y). Koefisien korelasi dalam variabel $\mathrm{X}_{8}$ ini adalah 0,299 , di mana dalam kisaran nilai ini menunjukkan kedekatan hubungan dalam kategori yang cukup. Arah korelasi antara variabel $\mathrm{X}_{8}$ dan $\mathrm{Y}$ menunjukkan nilai positif, sehingga variabel $\mathrm{X}_{8}$ yang lebih tinggi atau lebih rendah berkorelasi dengan kenaikan atau penurunan Y. Hal ini diduga karena responden menganggap bahwa budidaya gandum secara keseluruhan relatif mudah jika dilakukan dengan cara yang benar sehingga persepsi petani tentang kondisi lingkungan tidak berkorelasi dengan persepsi petani tentang budidaya gandum. Hasil yang diperoleh dari analisis korelasi menunjukkan bahwa variabel status petani, motivasi dan luas lahan memiliki korelasi dengan persepsi petani dalam budidaya gandum (Y).

Variabel motivasi (Z), diketahui memiliki nilai signifikansi 0,015 , dimana nilai ini $<0,05$ sehingga dapat dikatakan bahwa variabel motivasi berkorelasi signifikan dengan persepsi petani dalam budidaya gandum (Y). Nilai koefisien korelasi yang didapat adalah $0,440^{*}$, dimana nilai dalam rentang ini menunjukkan korelasi antara $\mathrm{Z}$ dan $\mathrm{Y}$ dalam tingkat cukup.
Arah korelasi antara variabel $\mathrm{Z}$ dan $\mathrm{Y}$ adalah positif, sehingga kenaikan atau penurunan nilai pada variabel $Z$ sejalan dengan penurunan atau peningkatan Y. Hasil ini juga berbanding lurus dengan penelitian sebelumnya dimana variabel persepsi petani berpengaruh nyata terhadap respons petani terhadap inovasi budidaya sorgum (Wijayanti et al, 2015).

\section{KESIMPULAN}

Kesimpulan dari penelitian ini adalah:

1. Responden di Kabupaten Demak cenderung memiliki persepsi bahwa budidaya gandum sangat tidak menguntungkan, tidak mudah diolah dan memiliki risiko kegagalan panen yang tinggi. Responden di Boyolali cenderung memiliki persepsi bahwa gandum mudah dibudidayakan, tetapi memiliki risiko kegagalan panen yang tinggi dan harga jual yang tinggi. Responden di Kabupaten Klaten cenderung memiliki persepsi bahwa budidaya gandum tidak menguntungkan dan memiliki risiko kegagalan panen yang tinggi, tetapi memiliki harga jual yang tinggi.

2. Ada hubungan yang signifikan antara variabel status petani $\left(\mathrm{X}_{4}\right)$, luas lahan $\left(\mathrm{X}_{6}\right)$, dan persepsi petani dalam budidaya gandum (Y). Persepsi petani berhubungan dengan motivasi petani untuk mengolah gandum (Z). Tidak ada hubungan yang signifikan pada umur $\left(\mathrm{X}_{1}\right)$, pendidikan $\left(\mathrm{X}_{2}\right)$, pengalaman bertani $\left(\mathrm{X}_{3}\right)$, frekuensi konseling $\left(\mathrm{X}_{7}\right)$, dan kondisi lingkungan pertanian $\left(\mathrm{X}_{8}\right)$ pada persepsi petani tentangbudidaya gandum (Y). 


\section{DAFTAR PUSTAKA}

Ahmadi, A. 2007. Psikologi Sosial. Rineka Cipta, Jakarta.

Ansari, Mohammad Aslam, Sharad Joshi, Rupan Raghuvanshi. 2018. Understanding Farmers Perceptions about climate Change: a Study in a North Indian State. Advances in Agriculture and Environmental Science: Open Access. Ology Press.

Burgess, P. 1971. Reasons for adult participation in group educational activities. Adult Education. 22 (1) 3-29.

Fauziyah, Elys. 2011. Manajemen Risiko pada usahatani Padi sebagai Salah Satu Upaya dalam mewujudkan Ketahanan Pangan Rumahtangga (Studi Kasus di Desa Telang Kecamatan Kamal. http:/ /pertanian.trunojoyo.ac.id.

Ginting, M., Thomson, S., dan Iskandarini. 2011. Farmer Social Economics Factors Analysis toward Lan area of Bawang Merah based upon Farmer Opinion in Dairi Regency. Thesis of Agribusiness Program, Agriculture Faculty. USU.

Ihsannudin. 2010. Risiko Usahatani Tembakau di Kabupaten Magelang. Embryo Vol. 7. No. 1. http://pertanian. trunojoyo.ac.id.

Kurnia, Theresa Dwi, Nugraheni Widyawati, Djoko Murdono, Endang Pudjihartati. 2016. Agronomic Traits of Wheat (Triticum Aestivum L) Genotypes in Tropical Lowland in Indonesia. AGRIC Vol. 28 No. 1 dan 2. 2016: 95104.
Liu, Hongbin and Xiaojuan Luo. 2018. Understanding Farmers' Perceptions and Behaviors towards Farmland Quality Change in Northeast China: A Structural Equation Modelling Approach.Sustainability.www.mdpi.com/ journal/sustainability.

Morgan, C.T. 1966. A Brief Introduction to Psychology. Mc. Graww-Hill Book Company. New York.

Nugroho, Adi Setyo, Ananto Aji, Ariyani Indrayati, 2017. Perubahan Penggunaan Lahan Sawah Menjadi Non Sawah dan Pengaruhnya terhadap Keberlanjutan Sawah Lestari di Kabupaten Klaten. Geo Image (SpatialEcological-Regional) 6(2)(2017). http:/ /journal.unnes.ac.id/sju/index.php/ geoimage.

Nur, A., Khumaida, N., Yahya, S., 2012. Evaluation and Genetics Variations of 12 Wheat Genotypes, Introduction in Wet Tropical Environment. Agrivigor 11: 230-243.

Roger, E.M., dan F.F, Shoemaker. 1971. Communication of Innovation. A Cross Cultural Approach.The Free Press. New York.

Rogers, E. M. 1995. Diffusion of Innovations. New York: The Free Press,

Sam, U.S., Ali M.S.S, Arsyad, M. 2018. Farmers Perceptions to Organic Lada Farming and Non-organik. Agriculture Social Economics Journal 14(2): 121 - 132.

Soekartawi, 2005. Fundamental Principles of Agriculture Communication. UI Press. Jakarta. 137 pages. 
Sugiarta, Putu, IGAA Ambarawati, I Gede Setiawan Adi Putra. 2017. Pengaruh Kinerja Penyuluh Pertanian terhadap Perilaku Petani pada penerapan Teknologi PTT dan Produktivitas Padi di Kabupaten Buleleng. Jurnal Manajemen Agribisnis Vol 5 No. 2 Oktober 2017: 34-42.

Wijayanti, Alvitri, Subejo, Harsoyo. 2015. Respons Petani terhadap Inovasi Budidaya dan Pemanfaatan Sorgum di Kecamatan Srandak Kabupaten Bantul. Agro Ekonomi 26, No 2, Desember 2015: 179-191.
Widiyastuti, Widianti, E., Sutarto. 2016. Farmers Perceptions toward System of Rice Intensification (SRI) in Moga sub district, Pemalang regency. Agrista Journal 4(3) September 2016 p. 476- 48.

Winardi. 2000, Kepemimpinan Dalam Manajemen Jakarta. Rineka Cipta.

Zulvera. 2014. Faktor Penentu Adopsi Sistem Pertanian Sayuran Organik dan Keberdayan Petani di Provinsi Sumatera Barat. Disertasi. http:// repository.ipb.ac.id/handle/123456789/ 70102. Bogor: IPB. 